\title{
THY Hisse Senedi Değerinin Yapay Sinir Ağları İle Kestirimi
}

Eda ÇINAROĞLU ${ }^{1}$

Tunahan AVCI ${ }^{2}$

\begin{tabular}{|c|c|c|}
\hline $\begin{array}{c}\text { Geliş Tarihi/ Received } \\
21 / 02 / 2019\end{array}$ & $\begin{array}{c}\text { Kabul Tarihi/ Accepted } \\
11 / 12 / 2019\end{array}$ & $\begin{array}{c}\text { Yayın Tarihi/ Published } \\
25 / 01 / 2020\end{array}$ \\
\hline $\begin{array}{l}\text { itation/Atıf: Çınaroğlu, E. } \\
\text { lestirimi, Atatürk Üniver } \\
0.16951 / \text { atauniiibd. } 530322\end{array}$ & $\begin{array}{l}\text { (2020), THY Hisse Se } \\
\text { isadi ve Idari Bilim }\end{array}$ & $\begin{array}{l}\text { gerinin Yapay Sinir Ağları İle } \\
\text { ergisi, } 34(1): \quad 1-20, \quad \text { DOI }\end{array}$ \\
\hline
\end{tabular}

Öz: Bu çalışmada, BİST’de işlem gören Türk Hava Yolları işletmesinin hisse senedi değerleri, günümüz finans piyasalarında yaygın olarak kullanılan Yapay Sinir A ̆̆ı (YSA) Modelleri ile tahmin edilmeye çalışılmıştır. Çalışma kapsamında 2015-2018 dönemine ait günlük veriler kullanılarak hisse senedi değerleri farklı YSA modelleri ile öngörülmüss, bu değerler aynı dönem gerçekleşen değerlerle karşılaştırılarak en başarılı YSA modeli belirlenmiştir. Analizde çıktı olarak hisse senedi değeri, girdi olarak ise BIST 100 ile BIST Ulaştırma Endeksleri, petrol ve dolar fiyatları kullanılmıştır. Uygulama aşamasında haftanın ilk 4 gününe ait değerler eğitim verisi, cuma gününe ait değerler ise test verisi olarak seçilmiş̧ir. Çalışmanın devamında en başarılı model kullanılarak 2019 yılı ocak ayına ait ilk 10 işlem günü için hisse senedi tahmin değerleri oluşturulmuştur. Bulgular, THY'ye ait gerçek hisse senetleri değerlerinin tahmin edilen hisse senetleri değerlerine çok yakın olduğunu ortaya koymuştur. Anahtar Kelimeler: Yapay Sinir Ağları, İstatistiksel Tahmin Modelleri, THY, Finansal Analiz, Hisse Senetleri.

The Forecasting of Thy Stock Value With Artificial Neural Networks

Abstract: In this study, the stock values of the Turkish Airlines business traded on the BIST are predicted with the Artificial Neural Network (ANN) Models. These models are widely used in today's financial markets. By using daily data belonging to 2015-2018 period, stock values are predicted with various ANN models and the most successful ANN model has been determined by comparing these values with the values realized in the same period. In the analysis, the stock value is used as an output, while BIST 100 and BIST Transportation Indexes, oil and dollar prices are used as inputs. The values of the first 4 days of the week are selected as training data and the values of fridays are selected as the test data. Afterwards, stock estimation values are predicted for the first 10 transaction days of January 2019 by using the most successful model. The findings show that the real stocks values of THY are very close to the estimated stocks values.

Keywords: Artificial Neural Networks, Statistical Forecast Models, THY, Financial Analysis, Stocks.

\footnotetext{
${ }^{1}$ Dr. Öğr. Üyesi, Erciyes Üniversitesi, Havacılık ve Uzay Bilimleri Fakültesi, Havacılık Yönetimi Bölümü. https://orcid.org/0000-0002-2904-3376

${ }^{2}$ Dr. Öğr. Üyesi, Erciyes Üniversitesi Havacılık ve Uzay Bilimleri Fakültesi, Havacılık Yönetimi Bölümü. https://orcid.org/0000-0003-0434-5834
} 
THY Hisse Senedi Değerinin Yapay Sinir Ağları İle Kestirimi

\section{Background}

\section{EXTENDED SUMMARY}

Transportation sector has an important place in the economy of our country. Considering the safety, speed and comfort factors in different transportation modes, airway transportation attracts attention with its advantageous position. The stocks of the enterprises in this sector, which is growing rapidly, both in the world and in our country, attract great attention from investors. Macroeconomic factors and some variables specific to the micro-sector cause changes in the value of these stocks. In order to minimize financial risk in the context of economic uncertainty, accurate estimation of the value of stocks is very important for investors.

Although there are traditional analysis methods used for stock value estimation, artificial neural networks (ANNs) are known to have better results than these methods.

Turkish Airlines Corporation (THY), the center of Turkey's national flag carrier airline company is located in Istanbul. It is one of the leading aviation companies followed by foreign investors. The fact that it is among the top 5 companies with the highest transaction volume in Borsa İstanbul is an indication of this interest.

\section{Purpose}

In this study, the predictability of stock values of Turkish Airlines listed on BIST is investigated. In this way, it is tried to find out whether it is possible to transfer information to investors. In this context, it is aimed to determine the ANN network model which best expresses the relationship between input variables and stock value.

\section{Method}

In the analysis, the stock values of the Turkish Airlines Corporation (THY) are estimated by using artificial neural network method. Different rule structures are tested by using LM and BR learning algorithms in artificial neural networks. Oil prices, dollar exchange rate, BIST transportation index and BIST 100 index values are determined as input variables of the model. The output variable of the model is the THY stock market value. As the analysis period, a period of 4 years (1008 days) is selected between 02.01.2015-31.12.2018.

\section{Findings}

The estimation success of the models established in the study is based on the Mean Square Error (MSE) values. It is concluded that the best MSE values obtained from the ANN techniques using the LM learning algorithm are (0.0031) for the educational data and (0.0030) for the test data. The best MSE values obtained by using BR learning algorithm are (0.0024) for educational data and (0.0023) for test data. It is found that the error value of stock value estimations made using BR learning algorithm is lower. The model with the highest stock forecasting success is a $4 \times 5$ rule structure using BR learning algorithm.

After the learning process is completed, the model is used on a new 10-days test data. MSE value of this model is found as 0.0016 . 


\section{Conclusions}

It is concluded that the best MSE values obtained for a time period of 1008 days are $(0.0031)$ for training data and $(0.0030)$ for test data. After the learning process is completed with the training and test data, the model is used on a new 10days test data. It has been calculated that there is a deviation of 0.0336 Turkish Liras (TL) for the 10 trading days between the realized stock values and the estimated values of the model. In other words, the success level of the model on the new test data is found to be higher.

The results of the analysis prove that ANN is meaningful to predict the behavior and tendencies of stocks, and that it can be used with other techniques to reveal market behavior and provide information to investors.

\section{Giriş}

Ulaştırma sektörü ülkemiz ekonomisinde önemli bir yere sahiptir. Farklı ulaştırma türleri içerisinde güvenlik, hız ve rahatlık faktörleri göz önünde bulundurulduğunda havayolu ulaşımı avantajlı konumu ile dikkat çekmektedir. Gerek dünyada, gerekse ülkemizde hızlı bir ivme ile büyüyen bu sektör içerisinde yer alan işletmelerin hisse senetleri de yatırımcılar tarafindan büyük ilgi görmektedir. Makroekonomik faktörler ile mikro nitelik arz eden sektöre özgü bazı değişkenler bu hisse senetlerinin değerlerinde değişime neden olmaktadır. Ekonomik belirsizlik ortamında finansal riskin en aza indirgenmesi adına hisse senetlerinin değerinin isabetli tahmini yatırımcılar için oldukça önemlidir.

Hisse senedi değer tahmini için kullanılan geleneksel analiz yöntemleri var olmakla birlikte, yapay sinir ağlarının (YSA) bu yöntemlere kıyasla daha iyi sonuçlar elde ettiği bilinmektedir. YSA'lar ile daha doğru tahminler üretilmesinin altında yatan nedenin değişkenler arasında var olan karmaşık ve non-lineer ilişki olduğu ifade edilmektedir (Çalışkan ve Deniz, 2015: 178). Yöntem doğrusal olmayan yapısı ve kendisine has eğitim sürecinin beraberinde getirdiği avantajları sayesinde son yıllarda çok farklı alanlardaki karmaşık problemlerin çözümünde tercih edilir olmuştur (Akel, 2012: 87). Finansal verilerin analizinde ve tahmin problemlerinde de sıklıkla kullanılmaktadır (Özkan, 2012: 28).

Türk Hava Yolları Anonim Ortaklığı (THY), merkezi İstanbul'da bulunan Türkiye'nin bayrak taşıyıcı ulusal hava yolu işletmesidir. Özellikle yabancı yatırımcılar tarafından takip edilen havacılık şirketlerinin başında gelmektedir. Borsa İstanbul'da en fazla işlem hacmine sahip olan ilk 5 firma içerisinde yer alması bu ilginin bir göstergesidir.

Havacılık sektörünün, aynı zamanda THY'nin faaliyetleri yapısı gereği petrol ve dolar fiyatlarından önemli düzeyde etkilenmektedir. Havayolu işletmelerinin en önemli giderinin petrol olması, yine satın alınan uçakların ve diğer ekipmanların dolar üzerinden satın alınması THY'nin maliyetlerine yansımakta, dolayısıyla karlılı̆̆ına etki etmektedir. Bu bağlamda petrol ve dolar fiyatlarındaki değişim THY'nin hisse senetlerinin performansını da yakından ilgilendirmektedir. THY'nin BIST 100 ve Ulaştırma Endeksi'nde yer alıyor olması nedeniyle bu endekslerin yönü 


\section{THY Hisse Senedi Değerinin Yapay Sinir Ağları İle Kestirimi}

de hisse senetlerinin fiyatını etkilemektedir. Bu bağlamda Türkiye borsasında en fazla işlem hacmine sahip olan bu işletmenin hisse senetlerinin değerinin tahmin edilmesinde belirtilen değişkenlerin esas alınması önemlidir.

Çalışmada BISST'de işlem gören THY işletmesinin hisse senedi değerlerinin önceden tahmin edilerek, yatırımcılara bilgi aktarımının mümkün olup olmadığını araştırılmıştır. Bu bağlamda girdi değişkenleri ile hisse senedi değeri arasındaki ilişkiyi en iyi ifade eden YSA a $\breve{g}$ modelinin tespiti amaçlanmıştır. Modeller kurulurken 2015-2018 yılları arasındaki zaman dilimine ait günlük veriler kullanılmıştır. Haftanın ilk dört gününe ait değerler eğitim verisi, cuma günü değerleri ise test verisi olarak kullanılmıştır. Eğiim ve test verilerinin farklı bir yapıda olup olmadığının kontrolü korelasyon analizi ile gerçekleştirilmiştir. Gerçekleşen hisse senedi değerleri ile tahmini hisse senedi değerleri karşılaştırılarak oluşturulan modellerin performansları kıyaslanmış, en düşük hata payına sahip olan model belirlenmiştir. Sonrasında hisse senedi değer tahmininde en yüksek başarıya ulaşan bu modelin doğrulanması adına yeni bir veri seti çalışmaya dahil edilmiştir. 2019 yılı ocak ayına ait ilk 10 işlem günü için bu model ile oluşturulan tahminler, gerçekleşen hisse senedi değerleri ile kıyaslanarak modelin tahmin başarısı teyit edilmiştir.

Çalışmanın ilerleyen bölümlerinde öncelikle hisse senedi değer tahmininde yapay sinir ağları kullanılarak yapılan çalışmaları içeren literatür taramasına yer verilmiştir. Ardından YSA teorisi açıklanmıştır. Uygulama bölümü yapılan analiz çalışmalarını içermektedir. Son bölümde ise analiz sonuçlarına ilişkin değerlendirme ve öneriler sunulmuştur.

\section{Literatür Taraması}

Yapay sinir ağının kullanıldığı çalışmada Donaldson ve Kamstra (1997) Londra, New York, Tokyo ve Toronto piyaslarındaki hisse senetlerinin oynaklığını ve değişkenliğini tahmin etmeye çalışmışlardır. Benzer olarak çalışmalarında Cao, Leggio ve Schniederjans (2005), Şanghay borsasında işlem gören şirketler için hisse senedi fiyat hareketlerini tahmin etmişlerdir. Sinir ağları modellerin kullanıldı̆̆ 1 çalışmalarında Mostafa (2010), Chen, Leung ve Daouk (2003) borsa fiyat hareketlerinin tahminini yapmışlardır.

Olson ve Mossman (2003), Roh (2007) çalışmalarında hisse senetlerinin getirilerinin tahmin edilmesinde yapay sinir ağları modellerinin üstünlüğünü ortaya koymuşlardır.

Tektaş ve Karataş (2004) İMKB'de işlem gören yedi hisse senedinin fiyat tahmininde doğrusal regresyon ve YSA yöntemlerini kullanarak bu yöntemleri kıyaslamışlardır. Çimento ve gıda sektörlerinde faaliyet gösteren işletmelere ait olan hisse senetleri öngörüsünde hem haftalık, hem de günlük veriler ile modeller geliştirilmiştir. Günlük veri kullanımının daha başarılı sonuçları beraberinde getirdiği ifade edilmiştir. Doğrusal regresyon yöntemlerine kıyasla YSA tekniğinin daha düşük hata payı ile daha yüksek tahminleme performansına ulaştığı saptanmıştır. 
Bovespa endeksinin tahmininin yapıldığı çalışmalarında Braga vd. (2007), tahmin için ileriye dönük bir ağ modeli oluşturmuş̧lardır. Analiz sonuçlarına göre modelle elde edilen MRE'nin (ortalama bağıl hata) 1.85 olduğunu belirtmişlerdir.

Toraman (2008) hisse senetleri İMKB'de işlem gören ve demir çelik endüstrisinde faaliyet gösteren iki büyük işletmenin hisse senedi fiyatlarının kapanış değerlerinin tahminlemesinde yapay sinir ağ 1 modellerinden faydalanmıştır. Çok katmanlı algılayıcı modelinin tercih edildiği analizler sonucunda iki şirket için ulaşılan ortalama mutlak yüzde hata $\% 1.42$ ve \% 1.69 iken; ortalama mutlak hata ise 12 kuruş ve 1.97 kuruş olarak hesaplanmıştır.

Vaisla ve Bhatt (2010), Hindistan borsasında işlem gören hisse senetlerine ait fiyat tahminine ilişkin çalışmalarında YSA tekniğinin tahmin başarısının regresyon modellerine kıyasla 9 kat fazla olduğu sonucuna ulaşmışlardır.

Akcan ve Kartal (2011) yapay sinir ağı modellerinin kullanımı ile İMKB'de sigorta sektörü endeksini oluşturan 7 şirketin hisse senedi fiyatlarını 15 günlük, 1 aylık, 1.5 aylık ve 2 aylık periyotlarda tahmin etmeyi amaçlamışlardır. 4 adet makro, 8 adet mikro nitelikte girdi değişkeninin yer aldığı analizde çok katmanlı algılayıcı modeli kullanılmıştır. Çalışmada en iyi sonuçlara 15 günlük tahminlemelerde ulaşılmış olup; bu tahminlerde ortalama mutlak yüzde hata $\% 0.85$ ile $\% 2.36$ arasında değişmekte iken; ortalama mutlak hata ise 2 kuruş ile 27 kuruş arasında değişen değerler almıştır. Tahmin süresi arttıkça tahmin başarısının azaldığ 1 ifade edilmiştir.

Cao vd., (2011) çalışmalarında Çin'de hisse senedi getirilerini tahmin etmek için doğrusal tabanlı modeller (ARIMA, sermaye varlıkları fiyatlandırma modeli ve Fama ile French'in üç faktörlü modeli) ile doğrusal olmayan modellerden yapay sinir ağ1 modellerini karşılaş̧ırmışlardır. 1999-2002 ve 2003-2008 dönemlerini içeren analizde sonuçlar hisse senedi piyasasının kendine özgü faktörlerinin etkisini yeterince yakalamak adına doğrusal olmayan bir işlevsel formun gerekli olduğunu destekler niteliktedir. Yani yüksek risk seviyeleri ile karakterize edilen piyasalarda da, lineer modellere göre sinir ağı modellerinin, hisse senedi fiyat hareketlerinin tahmininde daha yüksek başarı elde ettiği saptanmıştır.

Khansa ve Liginlal (2011), 1996-2008 yıllarını içeren dönemde bilgi güvenliği sektöründe faaliyet gösteren 88 işletmenin hisse senedi getirilerinin tahmini üzerinde çalışmışlardır. Hem vektör otoregresyon (VAR), hem de YSA modellerinin kullanıldığ 1 analizde kötü niyetli saldırıların bilgi güvenliği firmalarının borsa getirilerine etkisi incelenmiștir. Çalışmada bilgi güvenliği sektöründeki firmaların hisse senedi fiyat tahmininde YSA tekniğinin tahmin başarıs1 \%95, VAR modelinin tahmin başarısı ise $\% 85$ olarak tespit edilmiştir.

Dayı ve Ata (2012) çalışmalarında İMKB'de işlem gören imalat sanayi şirketlerinden Ereğli Demir ve Çelik Türk Fabrikaları A.Ş.' nin 1991-2010 yı1larını içeren döneme ait verilerini kullanarak, ulaştıkları en üstün öngörü performansına sahip YSA modeli ile 2011 yılı tahminlerini gerçekleştirmişlerdir. Analiz sonuçları incelendiğinde eğitim aşaması sonucunda $\% 96$, doğrulama aşaması sonucunda $\% 93$ ve test aşaması sonucunda $\% 87$ oranında başarılı tahminler oluşturulduğu tespit 


\section{THY Hisse Senedi Değerinin Yapay Sinir Ağları İle Kestirimi}

edilmiştir. Sonuçların tümü dikkate alındığında modelin tahmin başarısının \% 92 düzeyinde olduğu söylenebilir.

De Oliveira vd.,(2013) finansal piyasalarda mevcut olan bilgileri anlamak ve hisse senedi fiyatlarını yönlendiren değişkenleri tanımlamak amacıyla yaptıkları çalışmalarında YSA yönteminden faydalanmışlardır. BM \& FBOVESPA'da işlem gören Petrobras hisse senedinin kapanış fiyatlarının tahminini mümkün kılan modelde test seti için \%93.62, validasyon seti için \%87.50'lik başarı oranları elde edilmiştir. Modele ait ortalama mutlak yüzde hata değeri (MAPE) ise \%5.45'dir.

Çalışkan ve Deniz (2015) çalışmalarında BİST 30'da yer alan 30 hisse senedine ait günlük fiyatları ve fiyat değişim yönünü yapay sinir ağları tekniğini kullanarak analiz etmişlerdir. Çalışmada fiyat yönü tahmin başarısı \%58 iken; tahminlemede ortalama mutlak yüzde hata (MAPE) \%1.8, ortalama mutlak hata (MAE) ise 21 kuruş olarak bulunmuştur.

Yiğiter vd., (2017) 2006-2016 yılları arasında BİST'de işlem gören hisse senetlerinin kapanış fiyatlarını çoklu doğrusal regresyon, yapay sinir ağları ve bulanık mantık yöntemlerini kullanarak tahmin etmeye çalışmışlardır. Yapay sinir ağlarının diğer yöntemlere kıyasla daha başarılı sonuçlar verdiği belirtilmiştir. Bu modeller ile ulaşılan en iyi sonuca ait verimlilik katsayısı 0.823 olarak hesaplanmıştır.

Yapılan literatür araştırması sonucunda hisse senetlerinin fiyatlarının tahmin edilmesinde Tektaş ve Karataş'ın (2004) BIST 100 ve döviz kuru değişkenlerini, Akcan ve Kartal'ın (2011) BIST 100 ve döviz kuru değişkenlerini, De Oliveira vd.'nin (2013) döviz kuru ve petrol fiyatları değişkenlerini, Çalışkan ve Deniz'in ise (2015) BIST 100, döviz kuru ve petrol fiyatları değişkenlerini analize dahil ettikleri saptanmıştır. Yapılan çalışmada da bu değişkenlerin kullanımı uygun görülmüştür. Ek olarak THY işletmesinin ulaştırma sektörü içerisinde yer almasından dolayı BİST ulaştırma endeksinin de değişkenler arasına dahil edilmesine karar verilmiştir.

Literatür taraması sürecinde ulaştırma sektörü içerisinde yer alan havayolu işletmelerine ait hisse senedi değer tahmini konusunu içeren çalışmaların az sayıda olduğu tespit edilmiştir. Bu bağlamda sektöre özgü değişkenlerin esas alındığı çalışma literatüre farklılık katmaktadır. Yine literatürde yer alan çalışmalarda tek bir öğrenme algoritması ve tek tip katman sayısını esas alan modellerin kullanıldığı belirlenmiştir. Yapılan çalışmanın gerek farklı öğrenme algoritmaları, gerekse farklı katman yapılarının denenmesi açısından özgünlük içerdiği ifade edilebilir.

\section{Yöntem}

Yapay sinir ağları, biyolojik sinir ağının matematiksel olarak benzetimine dayanan yapay zekâ yöntemlerinden bir tanesidir. İnsan beyninin hesaplama ve öğrenme yeteneklerini taklit ederek yeni çıkarımlar yapabilme özelliği bulunan bir çeşit bilgi işleme mekanizmasıdır. Sahip olduğu öğrenme yoluyla yeni bilgiler türetme özelliğini, herhangi bir yardım almaksızın, otomatik bir şekilde gerçekleştirmek amacıyla geliştirilen bir bilgisayar sistemi olarak da tanımlanabilir. 
Geleneksel programlama yöntemleriyle bu yeteneklerin gerçekleştirilmesi oldukça güçtür, bazen de mümkün olamamaktadır. Bu nedenle programlanması çok güç olan ya da imkan dahilinde bulunmayan olaylar için adaptif bilgi işleme amaçlı YSA'lar geliştirilmiştir (Aygören vd., 2012: 77).

YSA'lar; örüntü tanıma, sınıflandırma, modelleme, optimizasyon ve tahmin gibi amaçlar için kullanılmaktadır (Rençber, 2018: 524). Hisse senetlerinin, altın ve döviz fiyatlarının tahmini, krizlerin öngörüsü, manipülatif işlemlerin tespiti, işletmelerin iflas edip etmeyeceğinin tahmini çalışma konularından bazılarıdır.

YSA'lar, doğrusal olmayan bir yapıya sahip olduklarından ve algoritmalar ile eğitilebildiğinden zor problemlerin çözümünde başarı göstermektedirler. Yine, analizlerden önce sağlanması gereken varsayımların olmaması, verilerde bilgi kaybına sebebiyet vermemesi ve deneme yanılma yoluyla daha iyi sonuçlara ulaşan modeller içermesi açısından başarısı yüksek teknikler arasında sayılmaktadır (Akcan ve Kartal, 2011: 32).

YSA'nın dezavantajları ise; (Karahan, 2011: 70-71)

- Bütün problemlerin çözümünde kullanılabilecek bir model olmaması, yani bazı problemlerin çözümünün bu teknik ile bulunamamas1,

- Probleme uygun olan ăg yapısını belirlerken genel olarak deneme yanılma yönteminin kullanılması,

- Bazı ağlarda ağın parametre değerlerini belirlerken subjektif davranması, yani mevcut bir kuralın olmamas1,

- Ağın, eğitimin bitirileceği zamana karar vermek için geliştirilmiş bir yöntem içermemesi,

- A $\breve{g}$ davranışlarının açıklanamama durumunun söz konusu olması, bir probleme yönelik çözüm üretildiğinde bunun neden ve nasıl üretildiği hakkında açık bilginin bulunamamas1,

- YSA'nın öğrenme süresinin uzun olması ve bir YSA'yı eğitmek için çok sayıda denemeye ihtiyaç duyulmasıdır.

Deneyimler ile öğrenme prensibi üzerine kurulan yapay öğrenme yaklaşımının esas alındığı YSA modelleri çoklu girdiden bir çıktı üretmeyi amaçlamaktadır. Tekniğin temel unsuru, nöron olarak adlandırılan işlemci elemanlardır (Bağış ve Konar, 2010: 105). A $\breve{g}$ içerisinde yer alan yapay sinir hücresi yani nöronlar; bir olayı verilere dayalı danışmanlı veya danışmansız öğrenerek, daha sonra hiç karşılaşmadığı benzer örnekler hakkında tahminde bulunabilen bir yapıya sahiptir. Nöronlar katman adı verilen mantıksal gruplar içerisinde konumlanmaktadır. Ağlar genellikle, üç veya daha fazla katmandan oluşan hiyerarşik bir yapıya sahiptir. Bu tip ağlarda 1 adet girdi katmanı, 1 ya da daha fazla gizli katman ve 1 adet çıktı katmanı bulunmaktadır (Kutlu ve Badur, 2009: 28). Sadece girdi ve çıktı katmanlarından oluşan tek katmanlı ağlar da mevcuttur. Her katmanda bulunan nöronlar bir sonraki katmanda yer alan nöronlarla bağlantılıdır. Sistemin amac1, girdi katmanından gelen verilere ait kalıpların tanınması yoluyla gerçek değere en yakın olan çıktının bulunmasıdır (Tektaş ve Karataş, 2004: 338). 


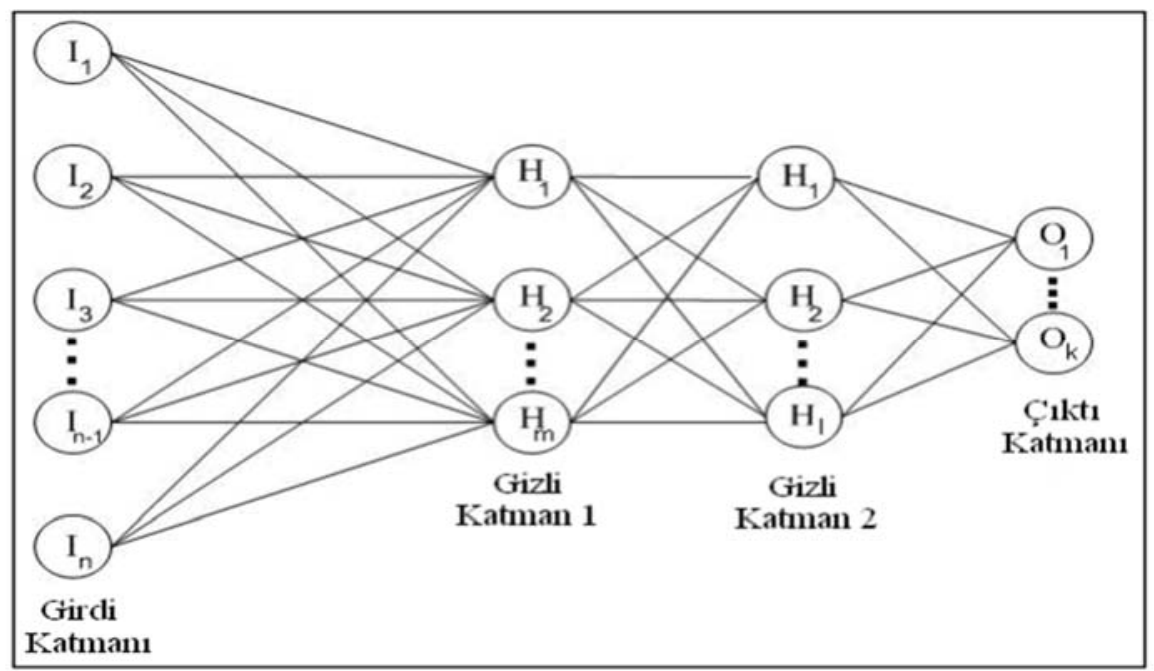

Şekil 1: Girdi, 2 Gizli ve 1 Çıktı Katmanı İle Oluşan Yapay Sinir A $\breve{g}$ ı

Çok katmanlı algılayıcılar (ÇKA) tahmin problemlerinde en sık kullanılan YSA türüdür. Çok katmanlı yapay sinir ağ 1 (ÇKYSA), nöronların birden çok gizli katman içerisinde birbirlerine bağlanarak oluşturdukları yapıyı ifade etmektedir. Yani ÇKYSA'larda girdi katmanı ile çıktı katmanı arasında birden fazla gizli katman yer almaktadır. Gizli katmanlar girdi katmanından gelen sinyallerin çıktı katmanına aktarımında görevli olup, dış ortamla bağlantı içerisinde değildirler (Budak ve Erpolat, 2012: 26).

Ağın çalışma prensibi şu şekilde açıklanabilir: Ağ üzerindeki her birim bir alt düzeyden kendisine iletilen girdi değerlerinin ağırlıklı toplamlarını hesaplar. Bu ağırlıklı toplam değeri girdi verilerinin bağlantı ağırlıkları ile çarpılması suretiyle bulunur. Veri ağ üzerinde yer alan her bir katmanda bu şekilde ilerler. Başlangıçta ağırlıklar rastgele belirlenir. İlk gizli katmanda çarpım sonuçları toplanır. Bu sonuç aktivasyon fonksiyonundan geçirilerek bir sonraki gizli katmana ya da çıtı katmanına iletilir. Aktivasyon fonksiyonu girdi değerinin işlenerek çıktı değerine dönüşmesi görevini üstlenen fonksiyondur. ÇKYSA'larda günümüzde en yaygın olarak kullanılan aktivasyon fonksiyonu 0 ile 1 arasında değişen çıktı sonuçları üreten sigmoid fonksiyonudur. Aktivasyon fonksiyonu yardımıyla gizli katmanlarda gerçekleştirilen bir dizi işlem süreci sonucunda ortaya çıkan ağın doğrusal olmayan yapıya dönüşme yeteneği, karmaşık problemlerin çözümünde fayda yaratmaktadır (Akel ve Karacameydan, 2012: 89). Verinin girdi katmanı sonrasında gizli katmanlar üzerinden çıktı katmanına iletilmesi ile süreç tamamlanır (Budak ve Erpolat, 2012: 26).

YSA'da sinıflandırma, modelleme, optimizasyon ya da tahmin gibi işlevlerin gerçekleştirilmesi için ağdaki bağlantı ayarlarının güncellenmesi işlemi öğrenme olarak isimlendirilmektedir. Ağın performansını arttırmak adına yapılan bu işlem 
bilgisayar programlarında iterasyonlar şeklinde yürütülmektedir. Öğrenme işlemi algoritmalar ile gerçekleştirilmektedir (Çalışkan ve Deniz, 2015: 179).

Öğrenme sürecinde çok katmanlı ileri beslemeli ağlar içerisinde en sık kullanılmakta olan algoritma geri yayılma olarak adlandırılan "Back Propagation" (BP) eğitim algoritmasıdır (Ticknor, 2013: 5502). Geri yayılım algoritması eğitim sürecinde iterasyonlar ilerlerken hedef çıktı değerleri ile ağ çıktı değerleri arasındaki farkın minimizasyonuna odaklanır, bu farkın en aza indirgenmesi için ağ bağlantı ağırlıklarının güncellenmesini esas alır. BP algoritmasının tahmin ve sinıflandırma işlemlerinde doğrusal olmayan yapılar için oldukça uygun ve kullanışlı olduğu bilinmektedir (Özkan, 2012: 31).

YSA'lar, eğitim esnasında sisteme dâhil olan örnekler üzerinden bir genelleme yapmaktadır. Problemde meydana gelen herhangi bir değişim sonrasında ise ağın tekrar eğitilmesi söz konusu olmaktadır. Ağın kendisini yeni durumlara karşı kolay uyarlayabilme özelliği hedef çıktıya hızlı şekilde ulaşabilme şansını beraberinde getirmektedir.

YSA'lar, her türlü bilgiyi işlemek veya analiz etmek için kullanılırlar. Matematiksel bir modele ihtiyaç duymadan ve kural sistemli bir yapı olmadan öğrenme yeteneği kazanabilen YSA'lar ile sınıflandırma, tahminleme veya modellemeler hızlı ve düşük maliyetli olarak gerçekleştirilebilmektedir (Ekinci vd., 2008: 23). Finansal piyasalara ait fiyatların günlük hareketlerinin dalgalı ve dinamik bir yapıda olması sebebiyle bu piyasaların yönünü tahmin etmede kullanımları oldukça uygundur (Altunöz, 2013: 203). Bu üstünlük esas alınarak, yapılan çalışmada etkin bir tahminleme modeli oluşturabilmek amacıyla, YSA yöntemi tercih edilmiştir.

\section{Analiz}

Yürütülen analizde BİST 100 ve BİST Ulaştırma Endeksi'nde yer alan THY işletmesine ait hisse senedi değerleri yapay sinir ağları yöntemiyle tahmin edilmeye çalışı1mıştır. İncelemede çalışmanın amacı ve gerçekleştirilen literatür araştırması esas alınarak petrol fiyatları, dolar kuru, BİST ulaştırma endeksi ve BİST 100 endeksi değerleri modelin girdi değişkenleri olarak belirlenmiştir. Oluşturulan modelin çıktı değişkeni ise THY hisse senedi piyasa değeridir. Analiz dönemi olarak 02.01.2015-31.12.2018 tarihleri arasındaki 4 yıllık (1008 gün) bir zaman periyodu seçilmiştir. Veriler içerisinde ilgili dönemdeki haftaların pazartesi, salı, çarşamba ve perşembe günü değerlerinden oluşan 808 adet veri eğitim seti olarak belirlenirken; cuma günü değerlerinden oluşan 200 adet veri ise test seti olarak belirlenmiştir. Bu bağlamda öncelikle test seti olarak seçilen cuma gününe ait hisse senedi değerlerinin, eğitim seti olarak kullanılan haftanın diğer günlerine ait hisse senedi değerlerine göre farklılık gösterip göstermediğinin kontrolü gerçekleştirilmiştir. Bu amaçla cuma günü hisse senedi fiyatlarının diğer günlere ait fiyatlar ile korelasyon katsayıları hesaplanmıştır. Tablo 1'de yer alan bu katsayı değerlerinin çok yüksek olduğu, dolayısıyla eğitim ve test verisinin homojenlik içerdiği belirlenmiştir. 
THY Hisse Senedi Değerinin Yapay Sinir Ağları İle Kestirimi

Tablo1. Korelasyon analizi

\begin{tabular}{|l|l|l|l|l|l|l|}
\hline \multicolumn{2}{|c|}{ Correlations } & Pazartesi & Salı & Carsamba & Persembe & Cuma \\
\hline Cuma & $\begin{array}{l}\text { Pearson } \\
\text { Correlation }\end{array}$ &, $992^{* *}$ &, $995^{* *}$ &, $998^{* *}$ &, $998^{* *}$ & 1 \\
\hline & $\begin{array}{l}\text { Spearman } \\
\text { Correlation }\end{array}$ &, $988^{* *}$ &, $991^{* *}$ &, $996^{* *}$ &, $997^{* *}$ & 1 \\
\hline \multirow{7}{|l}{. Correlation is significant at the 0.01 level (2-tailed). } \\
\hline
\end{tabular}

Analizde yer alan değişkenlere ait tanımlayıcı istatistikler Tablo 1'de yer almaktadır. Oluşturulan modellerde yer alan sınır değerleri BİST 100, BİST Ulaştırma, dolar, petrol ve THY hisse senedi değerleri için sırasıyla [68568, 120845], [49562,197673], [2.28,6.8], [27.88, 86.29] ve [4.63, 19.77] şeklindedir. Gerçek değerler bu sınır değerleri çerçevesinde $[0,1]$ aralığına normalize edilerek modelin daha başarılı sonuçlara ulaşması amaçlanmıştır. Normalizasyon adımında D-Min-Max yöntemi kullanılmıştır. Bu yöntem ile veri seti içerisindeki minimum değere sahip olan veri sıfır (0), maksimum değere sahip olan veri bir (1) normalize değerini alır. Yöntem diğer verilerin ise büyüklüklerine göre $0-1$ aralığında değerlere atanması mantığına dayanır.

Tablo 1. Analizde Kullanılan Değişkenlere Ait Tanımlayıcı İstatistikler

\begin{tabular}{|l|l|l|l|l|l|}
\hline & BIST_100 & BIST_Ulastırma & Dolar & Petrol & Thy \\
\hline Ortalama & 89696.08 & 100830.3 & 3.554375 & 56.21989 & 9.890665 \\
\hline Ortanca & 87026.40 & 89874.85 & 3.489100 & 54.64000 & 8.760000 \\
\hline Maksimum & 120845.3 & 197673.9 & 6.883400 & 86.29000 & 19.77000 \\
\hline Minimum & 68567.89 & 49562.46 & 2.281100 & 27.88000 & 4.630000 \\
\hline Gözlem sayısı & 1008 & 1008 & 1008 & 1008 & 1008 \\
\hline
\end{tabular}

YSA'da mevcut problemin çözümüne yönelik kullanılacak model için standart kurallar bulunmamaktadır. Bu sebeple modelde yer alması gereken katman sayıları; girdi, gizli ve çıktı katmanlarındaki nöron sayıları, öğrenme algoritması ve aktivasyon fonksiyonları deneme yanılma metodu ile belirlenmektedir (Y1ld1z, 2006: 39). YSA, tahmin amaçlı bir analize uygulanacaksa, genellikle çok katmanlı geri beslemeli ağ ile kullanılmaktadır. A $\breve{g}$ topolojisi oluşturulurken toplamda dört katmandan fazlası başarı performansını olumsuz yönde etkiyeceğinden daha fazla gizli katman ile deneme yapılmamıştır (Kaastra ve Boyd, 1996: 225).

YSA'ya dayalı olarak yapılan ve değişik sayıda gizli katman ve nöron sayıları ile gerçekleştirilen denemeler arasından, ulaşılan en iyi değerlere sahip ağ modellerine ait sonuçlar Tablo 2'de sunulmuştur.

Çok katmanlı yapay sinir ağı modelleri (ÇKYSA) içerinde tercih edilen ögrenme algoritmaları LM (Levenberg Marquart) ve BR (Bayesian Regulation) algoritmalarıdır. LM öğrenme algoritması daha az sayıda döngü ile daha kısa süre içerisinde eğitim sürecini tamamlama özelliğine sahiptir (Sönmez vd., 2015: 19). Bu 
algoritma maksimum komşuluk mantığ1 esasında oluşturulmuş en küçük kareler hesaplama metodu olarak da ifade edilebilir (Aslay ve Özen, 2013:142). BR algoritması ise LM algoritmasını temel alarak geliştirilen algoritmadır. Optimal seviyede ağ yapısının oluşturulmasında kolaylık sunmaktadır. Hata kareleri toplamını minimize etmek amacıyla çalışan, ağın genelleştirme yeteneği ile iyileştirilmiş bir algoritmadır (Erinci, 2016: 73).

Yapılan denemelerde gizli katmanda Hiperbolik Tanjant, çıktı katmanında ise Sigmoid aktivasyon fonksiyonlarının kullanılması durumunda başarılı sonuçlara ulaşılmıştır. Problemde oluşturulan her bir modelin eğitimi için 1000 adımlık (epoch) bir benzetim çalışması gerçekleştirilmiştir. Ortaya konulan her bir modelin eğitim ve test verileri için sergilediği minimum, ortalama ve maksimum yüzde hatalar Tablo 2'de yer almaktadır.

Tablo 2. Hisse Senedi Değeri Problemi İ̧̧in Farklı Model Performansları

\begin{tabular}{|c|c|c|c|c|c|}
\hline & \multicolumn{4}{|c|}{$L M$} \\
\hline & & 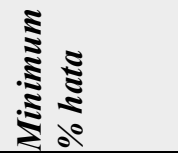 & 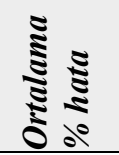 & 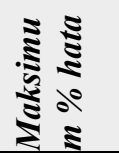 & $\sum_{2}^{\infty}$ \\
\hline \multirow{2}{*}{$(2 \times 2)$} & Eğitim & 0.0027 & 0.6714 & 2.7425 & 0.0058 \\
\hline & Test & $8.0422 \mathrm{e}-04$ & 0.6815 & 3.1214 & 0.0057 \\
\hline \multirow{2}{*}{$(2 \times 3)$} & Eğitim & 0.0030 & 0.5573 & 2.3063 & 0.0052 \\
\hline & Test & $2.7704 \mathrm{e}-04$ & 0.5671 & 1.8507 & 0.0050 \\
\hline \multirow[t]{2}{*}{$(2 \times 4)$} & Eğitim & $9.1162 \mathrm{e}-05$ & 0.5389 & 2.7697 & 0.0045 \\
\hline & Test & 0.0020 & 0.5531 & 2.5611 & 0.0042 \\
\hline \multirow[t]{2}{*}{$(2 \times 5)$} & Eğitim & 0.0020 & 0.6416 & 2.1036 & 0.0060 \\
\hline & Test & 0.0074 & 0.6352 & 1.8294 & 0.0058 \\
\hline \multirow{2}{*}{$(3 \times 2)$} & Eğitim & $3.0848 \mathrm{e}-04$ & 0.6068 & 2.4781 & 0.0054 \\
\hline & Test & $6.0226 \mathrm{e}-04$ & 0.6132 & 2.5777 & 0.0053 \\
\hline \multirow{2}{*}{$(3 \times 3)$} & Eğitim & $3.2870 \mathrm{e}-04$ & 0.5075 & 2.3639 & 0.0046 \\
\hline & Test & 0.0011 & 0.5216 & 2.0616 & 0.0045 \\
\hline \multirow{2}{*}{$(3 \times 4)$} & Eğitim & $8.6829 \mathrm{e}-04$ & 0.5914 & 2.8855 & 0.0045 \\
\hline & Test & $8.9849 \mathrm{e}-04$ & 0.5857 & 3.2669 & 0.0043 \\
\hline \multirow{2}{*}{$(3 \times 5)$} & Ĕgitim & $2.8136 \mathrm{e}-04$ & 0.4208 & 1.8009 & 0.0031 \\
\hline & Test & 0.0025 & 0.4368 & 1.8809 & 0.0030 \\
\hline \multirow{2}{*}{$(4 \times 2)$} & Eğitim & 0.0018 & 0.5177 & 2.2422 & 0.0042 \\
\hline & Test & $2.1056 \mathrm{e}-04$ & 0.5229 & 1.9015 & 0.0042 \\
\hline \multirow{2}{*}{$(4 \times 3)$} & Eğitim & $1.6947 \mathrm{e}-04$ & 0.4195 & 2.1428 & 0.0035 \\
\hline & Test & 0.0017 & 0.4468 & 1.7755 & 0.0034 \\
\hline \multirow{2}{*}{$(4 \times 4)$} & Eğitim & $2.3215 \mathrm{e}-04$ & 0.4111 & 1.5662 & 0.0031 \\
\hline & Test & $7.4886 \mathrm{e}-04$ & 0.4286 & 1.5650 & 0.0032 \\
\hline \multirow{2}{*}{$(4 \times 5)$} & Eğitim & $1.7775 \mathrm{e}-04$ & 0.4433 & 2.2025 & 0.0033 \\
\hline & Test & $4.1885 \mathrm{e}-04$ & 0.4526 & 2.8326 & 0.0032 \\
\hline
\end{tabular}


THY Hisse Senedi Değerinin Yapay Sinir Ağları İle Kestirimi

Tablo 2. Devamı: Hisse Senedi Değeri Problemi İçin Farklı Model Performanslart

\begin{tabular}{|c|c|c|c|c|c|}
\hline & \multicolumn{4}{|c|}{$B R$} \\
\hline & & 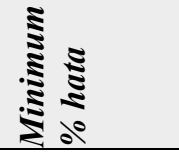 & $\begin{array}{c}\frac{9}{2} \\
\frac{2}{2} \\
2\end{array}$ & 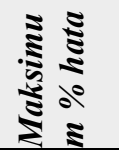 & 选 \\
\hline \multirow{2}{*}{$(2 \times 2)$} & Eğitim & $6.1214 \mathrm{e}-04$ & 0.6598 & 2.5873 & 0.0054 \\
\hline & Test & 0.0020 & 0.6642 & 2.8211 & 0.0053 \\
\hline \multirow{2}{*}{$(2 \times 3)$} & Eğitim & 0.0019 & 0.6499 & 3.2272 & 0.0055 \\
\hline & Test & 0.0063 & 0.6623 & 2.8010 & 0.0054 \\
\hline \multirow[t]{2}{*}{$(2 \times 4)$} & Eğitim & $8.4217 \mathrm{e}-04$ & 0.6402 & 2.7818 & 0.0052 \\
\hline & Test & 0.0043 & 0.6436 & 2.6466 & 0.0050 \\
\hline \multirow[t]{2}{*}{$(2 \times 5)$} & Eğitim & $5.3776 \mathrm{e}-05$ & 0.5859 & 3.2171 & 0.0048 \\
\hline & Test & 0.0049 & 0.5933 & 2.9973 & 0.0045 \\
\hline \multirow{2}{*}{$(3 \times 2)$} & Eğitim & 0.0016 & 0.6065 & 3.3866 & 0.0049 \\
\hline & Test & 0.0016 & 0.5954 & 2.6413 & 0.0046 \\
\hline \multirow{2}{*}{$(3 \times 3)$} & Eğitim & $9.1762 \mathrm{e}-04$ & 0.5711 & 2.5388 & 0.0048 \\
\hline & Test & 0.0054 & 0.5760 & 2.8237 & 0.0045 \\
\hline \multirow{2}{*}{$(3 \times 4)$} & Eğitim & 0.0035 & 0.5001 & 2.5739 & 0.0039 \\
\hline & Test & 0.0014 & 0.4977 & 2.6051 & 0.0037 \\
\hline \multirow{2}{*}{$(3 \times 5)$} & Ĕgitim & 0.0018 & 0.4515 & 1.9988 & 0.0037 \\
\hline & Test & 0.0026 & 0.4593 & 2.0787 & 0.0034 \\
\hline \multirow{2}{*}{$(4 \times 2)$} & Eğitim & $1.5321 \mathrm{e}-04$ & 0.4498 & 1.8777 & 0.0036 \\
\hline & Test & 0.0030 & 0.4764 & 2.0056 & 0.0034 \\
\hline \multirow{2}{*}{$(4 \times 3)$} & Eğitim & $6.5888 \mathrm{e}-04$ & 0.5218 & 3.1442 & 0.0039 \\
\hline & Test & 0.0025 & 0.5245 & 3.4251 & 0.0038 \\
\hline \multirow{2}{*}{$(4 \times 4)$} & Eğitim & 0.0013 & 0.4223 & 2.0564 & 0.0033 \\
\hline & Test & 0.0011 & 0.4306 & 1.8785 & 0.0031 \\
\hline \multirow{2}{*}{$(4 \times 5)$} & Eğitim & $5.9230 \mathrm{e}-04$ & 0.3629 & 1.7561 & 0.0024 \\
\hline & Test & $4.1041 \mathrm{e}-04$ & 0.3744 & 1.6669 & 0.0023 \\
\hline
\end{tabular}

Farklı modeller kullanılarak gerçekleştirilen tahminlerin isabet gücünün belirlenmesinde, modellerin tahmin sonuçlarından edinilen hata terimleri istatistikleri esas alınmaktadır. Hata terimi istatistiklerine ait değerler aynı bağımlı değişkeni açıklamaya çalışan farklı modellerin tahminleme başarısının kıyasını mümkün kılmaktadır (Özkan, 2012: 37). ÇKYSA'nın kullanılmasıyla oluşan modelleme hataları Eşitlik 1'de verilen hata kareleri ortalaması (Mean Square ErrorMSE) ile hesaplanmıştır. MSE hata fonksiyonları arasında uygulamada en sık kullanılan fonksiyondur (Ticknor, 2013: 5502). Bu performans kriterinin kullanımı ile modellenen yapının kalitesinin belirlenmesi mümkün olmuştur. 


$$
M S E=\frac{1}{N} \sum_{k=1}^{N}\left(O_{k}^{d}-O_{k}\right)^{2}
$$

(Eşitlik 1)

Eşitlik 1'de yer alan $O_{k}^{d}$ tahmin edilen çıkış değeri, $\mathrm{O}_{\mathrm{k}}$ gerçek çıkış değeri ve $\mathrm{N}$ ise örnek sayısını ifade etmektedir (Saraçoğlu vd., 2016: 40).

En uygun ağ yapısı, bu performans ölçütü esas alınarak, gerçekleşen değer ile tahmin bulgularının karşılaştırılması yoluyla tespit edilmiştir. ÇKYSA modelinde LM öğrenme algoritması kullanılarak 3x5'lik bir kural yapısıyla en iyi sonuçlar elde edilmiştir. Modelde $(3 \times 5)$ olarak gösterilen değerler gizli katmanlarda yer alan nöron sayılarını ifade etmektedir. ÇKYSA modelinde BR öğrenme algoritması kullanılarak ise $4 \times 5$ 'lik bir kural yapısıyla en iyi sonuçlara ulaşılmıştır.

YSA tekniklerinden LM öğrenme algoritması kullanılarak elde edilen en iyi MSE değerlerinin eğitim verileri için (0.0031), test verileri için ise (0.0030) olduğu sonucuna ulaşı1mıştır. BR öğrenme algoritması kullanılarak elde edilen en iyi MSE değerleri ise eğitim verileri için (0.0024), test verileri için (0.0023)'dir. BR öğrenme algoritması kullanılarak yapılan hisse senedi değer tahminlerinin hata payının daha düşük olduğu saptanmıştır. Hisse senedi tahmin başarısı en yüksek olan model BR öğrenme algoritması kullanılarak 4x5'lik bir kural yapısıyla oluşturulan modeldir. En iyi model performansı MSE'nin 0'a yaklaştığ 1 durumda gerçekleşmektedir (Aygören vd. 2012: 83). Bu bağlamda elde edilen MSE değerlerinin oldukça düşük ve kabul edilebilir düzeyde olduğu söylenebilir. Bu durum ilgili YSA modelinin tanımlanan amaç için kullanılabilir olduğunun göstergesidir (Yıldız, 2006: 66).

Analiz sonuçları Jabin (2014) çalışması ile büyük uyum göstermektedir. Jabin hisse senedi fiyat tahmininde ileri beslemeli geri yayılımlı ÇKYSA'lar için en yüksek başarı oranına ulaşan öğrenme algoritmasının ve diğer ağ parametrelerinin tespiti üzerine denemeler gerçekleştirmiştir. Çalışma, hisse senedi fiyatı tahmininde en uygun öğrenme algoritmasının BR algoritması olduğu sonucunu içermektedir. Girdi katmanında $\mathrm{n}$ adet, çıktı katmanında ise 1 adet nöron bulunan bir ÇKYSA'da en iyi sonuçlara gizli katmandaki nöron sayısının $2 n+1$ olması durumunda ulaşılabileceği ifade edilmiştir. Çalışmamızda girdi katmanında 4, çıktı katmanında 1 adet nöron bulunurken; tahmin performansı açısından en üstün olduğu saptanan modelin gizli katmanlarında yer alan nöron sayısı 9 adettir.

Modelde LM ve BR öğrenme algoritmaları kullanılarak oluşturulan hisse senetlerinin tahmini değerleri gerçek değerleri ile birlikte grafiksel olarak Şekil 1'de gösterilmiştir. Şekil 2'den, BR öğrenme algoritması kullanılarak oluşturulan hisse senedi tahmin değerlerinin gerçek değerler ile oldukça uyumlu olduğu gözlenmektedir. 
THY Hisse Senedi Değerinin Yapay Sinir Ağları İle Kestirimi

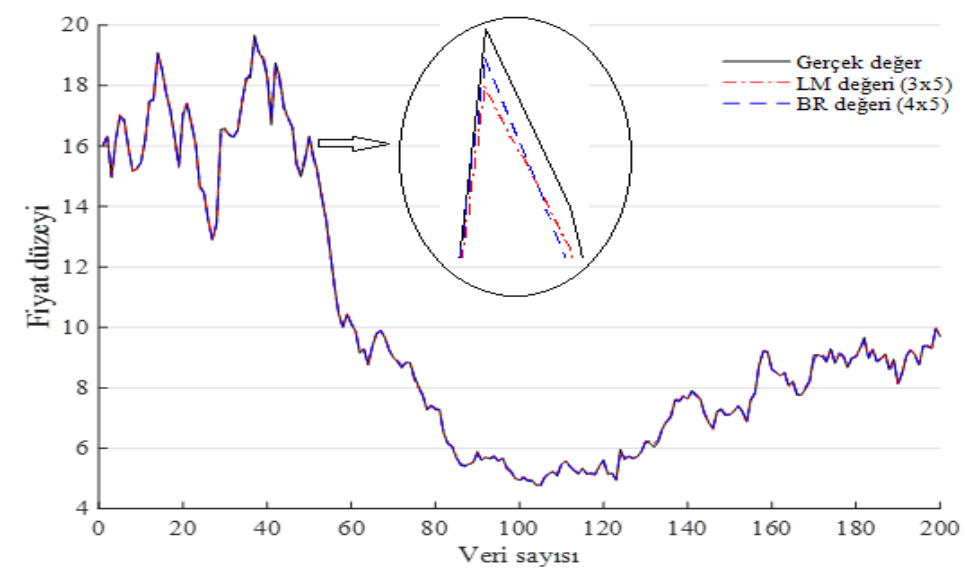

Şekil 2. Hisse Senetlerinin Tahmin Değerleri İle Gerçek Değerlerinin Aynı Grafikte Gösterimi

BR öğrenme algoritması kullanılarak 4x5'lik bir kural yapısıyla oluşturulan ve THY hisse senedi tahmininde en yüksek başarıyı elde eden modele ait her bir eğitim verisi için yapılan yüzde hata değerleri Şekil 3'de, her bir test verisi için yapılan yüzde hata değerleri ise Şekil 4'de grafiksel olarak gösterilmektedir.

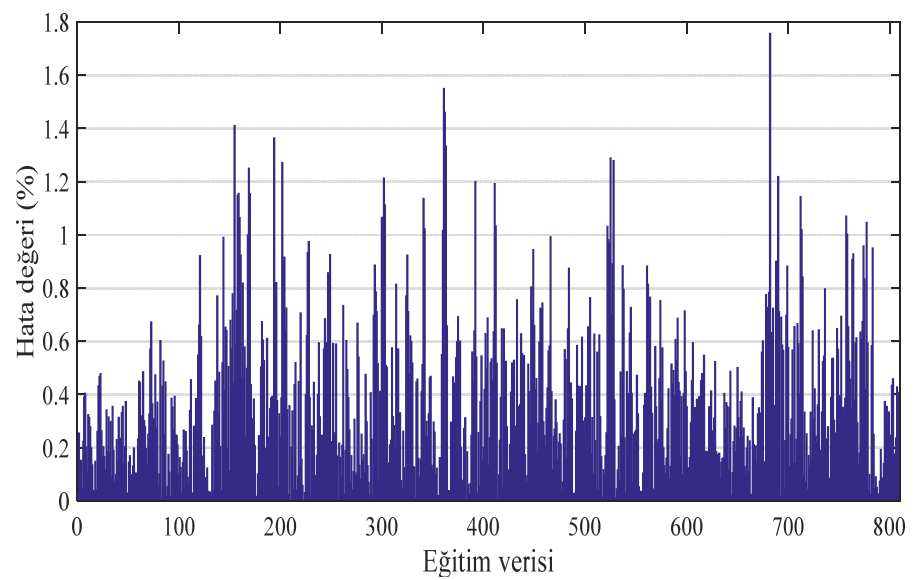

Şekil 3. Eğitim Verisinde Yapılan Yüzde Hata Değerleri (BR 4x5) 


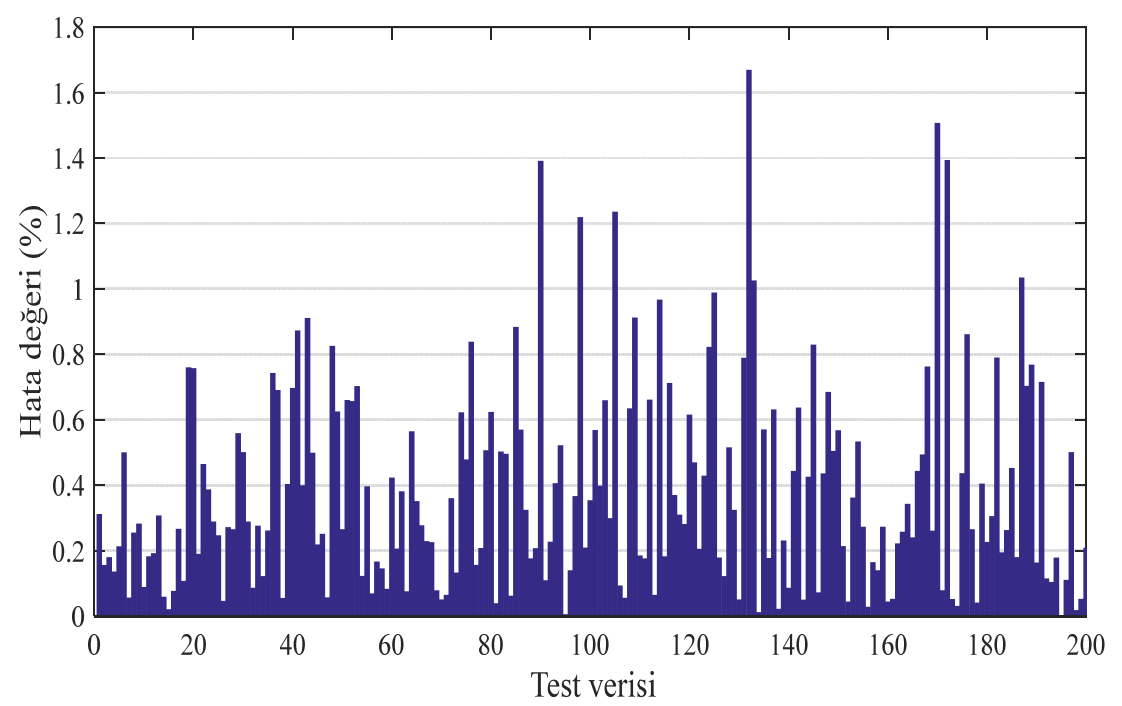

Şekil 4. Test Verisinde Yapılan Yüzde Hata Değerleri (BR 4x5).

Eğitim için yapılan yüzde hata değerlerinin gösterildiği Şekil 3'de minimum hata $5.923 \times 10^{-6}$, maksimum hata ise $1.7561 \times 10^{-2}$ olarak belirlenmiştir. Test verisi için yapılan yüzde hataların gösterildiği Şekil 4'de minimum hata $4.1041 \times 10^{-6}$, maksimum hata $1.6669 \times 10^{-2}$ olarak belirlenmiştir.

Kurulan ÇKYSA modelinin 1008 adet eğitim ve test verisi ile öğrenme işlemi tamamlandıktan sonra THY işletmesi hisse senetleri için 02.01.2019-15.01.2019 tarihleri arasındaki 10 işlem günü için fiyat tahminleri yapılmış olup, bu tahminlere ilişkin mutlak sapma ve yüzde hata değerleri Tablo 3'de gösterilmiştir.

Tablo 3: Hisse Senedi Yeni Test Verileri

\begin{tabular}{|l|l|l|l|}
\hline Gerçek Dĕ̌ er & Tahmini Dĕger & Mutlak Sapma & Mutlak \% Hata \\
\hline 15.7200 & 15.7683 & 0.0483 & 0.3073 \\
\hline 15.1400 & 15.2042 & 0.0642 & 0.4239 \\
\hline 15.1100 & 15.1748 & 0.0648 & 0.4290 \\
\hline 15.0600 & 15.0660 & 0.0060 & 0.0397 \\
\hline 15.1100 & 15.1180 & 0.0080 & 0.0530 \\
\hline 14.9500 & 14.9743 & 0.0243 & 0.1625 \\
\hline 14.9600 & 15.0120 & 0.0520 & 0.3475 \\
\hline 15.0800 & 15.0867 & 0.0067 & 0.0443 \\
\hline 15.0300 & 15.0143 & 0.0157 & 0.1042 \\
\hline 14.5900 & 14.5438 & 0.0462 & 0.3169 \\
\hline \multicolumn{2}{|c|}{ Ortalama } & 0.03362 & 0.22283 \\
\hline
\end{tabular}




\section{THY Hisse Senedi Değerinin Yapay Sinir Ağları İle Kestirimi}

Tablo 3'de görüldüğü gibi THY hisse senetleri için tahmin yapılan 10 işlem gününde ortalama mutlak hata $(\mathrm{OMH}) 3.36$ kuruş, ortalama mutlak yüzde hata $(\mathrm{OMYH})$ ise $\% 0.22$ olmuştur.

Modelin 10 günlük tahmini sonucunda ulaş1lan minimum $\%$ hata, ortalama \% hata, maksimum \% hata ve MSE değerleri Tablo 4'de yer almaktadır. Sifira oldukça yakın olan bu değerler modelin öngörü performansının yüksek olduğunu kanitlamaktadir.

Tablo 4. Yeni Test Verisi Model Performansı

\begin{tabular}{|l|c|c|c|c|}
\hline & Minimum \% hata & $\begin{array}{l}\text { Ortalama } \\
\text { \% hata }\end{array}$ & $\begin{array}{l}\text { Maksimum } \\
\text { \% hata }\end{array}$ & MSE \\
\hline $\begin{array}{l}\text { Yeni } \\
\text { Test }\end{array}$ & 0.0397 & 0.222 & 0.4290 & 0.0016 \\
\hline
\end{tabular}

Elde edilen sonuçlar, on gün için yapılan tüm tahminlerin başarılı olduğunu ortaya koymaktadır. Sonuç olarak THY hisse senedi fiyatlarının kestiriminde yapay sinir ağı modellerinin kullanımı ile yatırımcılara önceden bilgi sağlanarak yatırımlarına yön verilebileceği ortaya konulmuştur.

\section{Sonuç Ve Öneriler}

Finansal değişkenlerin tahmini amacıyla YSA modellerinin kullanımı gün geçtikçe artış göstermektedir. İstatistiksel varsayımlara ihtiyaç duymaması ve veri içerisindeki ilişki kalıplarını iteratif bir süreç içerisinde matematiksel bir model oluşturmaksızın öğrenmesi bu modellerin üstün yanını ortaya koymaktadır. Geleneksel tahmin tekniklerine göre daha az hata payı içeren YSA'ların hisse senedi değer tahmini amacıyla sıklıkla tercih edildiği bilinmektedir.

$\mathrm{Bu}$ çalışmada BİST ulaştırma endeksinde yer alan ve ülkemiz için bayrak taşıyıcı nitelik taşıyan THY işletmesinin hisse senedi değerleri tahmin edilmiştir. Haftanın ilk 4 gününe ait değerlerin kullanımı ile cuma gününe ait doğru tahminlerin yapılıp yapılmayacağı üzerinde durulmuştur. Yani haftanın ilk dört gününe ait değerler eğitim verisi, cuma gününe ait değerler ise test verisi olarak kullanılmıştır. Ancak cuma gününün kapanış günü olması sebebiyle farklı bir yapı gösterebileceği düşünülerek, öncelikle haftanın diğer günleri ile bu gün arasındaki korelasyon analizine ihtiyaç duyulmuştur. Korelasyon analizi sonuçları diğer günler ile cuma günü değerlerinin çok yüksek ilişki içerisinde olduğunu göstermiştir. Petrol fiyatları, dolar kuru, BİST ulaştırma endeksi ve BİST 100 endeksi değerleri YSA modelinin girdi değişkenleri olarak belirlenmiştir. Modelin çıktı değişkeni ise THY hisse senedi piyasa değeridir. Analiz dönemi olarak 02.01.2015-31.12.2018 tarihleri arasındaki 4 yıllık (1008 gün) bir zaman periyodu seçilmiştir. 1008 günlük bir zaman periyodu için elde edilen en iyi MSE değerlerinin eğitim verileri için (0.0031), test verileri için ise (0.0030) olduğu sonucuna ulaş1lmıştır. Modelin eğitim ve test verisi ile ögrenme işlemi tamamlandıktan sonra, 10 günlük yeni test verisi üzerinde kullanımı gerçekleştirilmiştir. Gerçekleşen hisse senedi değerleri ile modelin tahmini değerleri arasında 10 işlem günü için 3.36 kuruş düzeyinde sapma 
olduğu hesaplanmıştır. Yani modelin yeni test verisi üzerindeki başarı düzeyinin daha yüksek olduğu tespit edilmiştir.

Analiz sonuçları YSA'nın hisse senetlerinin davranış ve eğilimlerini öngörmek için kullanımının anlamlı olduğunu, piyasa davranışını ortaya koymak ve yatırımcılara bilgi sunmak amacıyla diğer tekniklerle birlikte kullanılmasının avantajları beraberinde getireceğini kanıtlamaktadır.

Literatür taraması sürecinde ulaştırma sektörü içerisinde yer alan havayolu işletmelerine ait hisse senedi değer tahmini konusunu içeren çalışmaların az sayıda olduğu tespit edilmiştir. Bu bağlamda sektöre özgü değişkenlerin esas alındığ 1 çalışma literatüre farklılık katmaktadır. Yine literatürde yer alan çalışmalarda tek bir öğrenme algoritması ve tek tip katman sayısını esas alan modellerin kullanıldığ belirlenmiştir. Yapılan çalışmanın gerek farklı öğrenme algoritmaları, gerekse farklı katman yapılarının denenmesi açısından özgünlük içerdiği ifade edilebilir.

Çalışmada endüstriye özgü girdi değişkenleri kullanılmış olup, bu değişkenler arasına işletmeye ait yeni değişkenlerin eklenmesiyle daha başarılı sonuçların elde edilmesi mümkün olabilecektir. İlerleyen çalışmalarda kurulması planlanan YSA modellerinde farklı girdi değişkenleri, ağ topolojileri ya da öğrenme algoritmalarının kullanımı ile elde edilecek hata değerlerinin mevcut çalışmaya ait değerlerle kıyası düşünülmektedir. Yine YSA ile diğer modellerin hisse senedi değer tahminindeki başarı düzeylerinin karşılaştırılması ilerleyen çalışmalarda konu edinilebilir.

\section{Kaynaklar}

Akbalık, M. \& Özkan, N. (2016) "Haftanın Günü Etkisi: BIST 30 Endeksi Payları Üzerine Bir Araştırma”, Finansal Araşstırmalar ve Çalışmalar Dergisi, 8(14). $1-16$.

Akcan, A. \& Kartal, C. (2011) "IMKB Sigorta Endeksini Oluşturan Şirketlerin Hisse Senedi Fiyatlarının Yapay Sinir Ağları İle Tahmini”, Muhasebe ve Finansman Dergisi, (51). 27-40.

Akel, V. \& Karacameydan, F. (2012) "Yatırım Fonları Net Varlık Değerlerinin Yapay Sinir Ağları Yöntemiyle Tahmin Edilmesi", Anadolu Üniversitesi Sosyal Bilimler Dergisi, Cilt/Vol.: 12 - Sayı/No: 2 (87-106)

Altunöz, U. (2013) "Bankaların Finansal Başarısızlıklarının Yapay Sinir Ağları Modeli Çerçevesinde Tahmin Edilebilirliği”, Dokuz Eylül Üniversitesi İktisadi ve İdari Bilimler Fakültesi Dergisi, 28(2).

Aslay, F. \& Özen, Ü. (2013) "Meteorolojik Parametreler Kullanılarak Yapay Sinir Ağları İle Toprak Sıcaklığının Tahmini”, Politeknik Dergisi, 16(4). 139-145.

Aygören, H., Saritaş, H. \& Morali, T. (2012) "İMKB 100 Endeksinin Yapay Sinir Ağları ve Newton Nümerik Arama Modelleri İle Tahmini”, Journal of Alanya Faculty of Business/Alanya İşletme Fakültesi Dergisi, 4(1).

Bağiş, A. ve Konar, M. (2010) "Uçuş Kontrol Sistemi Yakıt Parametresinin Yapay Sinir Ağları Kullanılarak Belirlenmesi”, Akıllı Sistemlerde Yenilikler Ve Uygulamaları Sempozyumu, 21-24 Haziran 2010, Kayseri\&Kapadokya, Türkiye. 
THY Hisse Senedi Değerinin Yapay Sinir Ağları İle Kestirimi

Braga, A., de Leon Ferreira, A. C. P., ve Ludermir, T. B. (2007), Redes Neurais Artificiais: Teoria E Aplicações, Rio de Janeiro, Brazil:: LTC Editora.

Budak, H. \& Erpolat, S. (2012) "Kredi Riski Tahmininde Yapay Sinir Ağları ve Lojistik Regresyon Analizi Karşılaştırılması", Ajıt-E: Online Academic Journal of Information Technology, 3(9). 23-30.

Cao, Q., Leggio, K., \& Schniederjans, M. (2005) “A Comparison Between Fama Andfrench's Model And Artificial Networks İn Predicting The Chinese Stock Market", Computers and Operations Research, 32, 2499-2512.

Cao, Q., Parry, M. E., ve Leggio, K. B. (2011) "The Threefactor Model And Artificial Neural Networks: Predicting Stock Price Movement İn China", Annals of Operations Research, 185(1), 25-44.

Chen, A., Leung, M., ve Daouk, H. (2003) "Application Of Neural Networks To Anemerging Financial Market: Forecasting And Trading The Taiwan Stock İndex", Computers and Operations Research, 30, 901-923

Çalışkan, M. M. T. \& Deniz, D. (2015) "Yapay Sinir Ağlarıyla Hisse Senedi Fiyatları ve Yönlerinin Tahmini”, Dokuz Eylül Üniversitesi İktisadi ve İdari Bilimler Fakültesi Dergisi, 31, 177-194.

Dayı, F. \& Ata, H. A. (2012) "Yapay Sinir Ağı İle Hisse Senedi Getirisi Tahmini: Bir Firma Uygulamas1", 16. Finans Sempozyumu. 10-13.

De Oliveira, F. A., Nobre, C. N., \& Zárate, L. E. (2013) “Applying Artificial Neural Networks To Prediction Of Stock Price And İmprovement Of The Directional Prediction İndex-Case Study of PETR4, Petrobras, Brazil", Expert Systems with Applications, 40(18), 7596-7606.

Donaldson, R. G., \& Kamstra, M. (1997) "An Artificial Neural Network-GARCH Model For İnternational Stock Return Volatility”, Journal of Empirical Finance, 4(1), 17-46.

Ekinci, Y., Temur, G. T., Çelebi, D., \& Bayraktar, D. (2008) "Ekonomik Kriz Döneminde Firma Başarısı Tahmini: Yapay Sinir Ağları Tabanlı Bir Yaklaşım”, Endüstri Mühendisliği Dergisi, Cilt: 21 Sayı: 1 (17-29)

Erinci, F. (2016) "Her Şey Dâhil Sisteminde Yiyecek İçecek Miktarlarının Yapay Sinir Ağları İle Tahmini. Alanya'da Bir Uygulama”, Doktora Tezi, Akdeniz Üniversitesi, Sosyal Bilimler Enstitüsü, Antalya.

Jabin, S. (2014) "Stock Market Prediction Using Feed-Forward Artificial Neural Network", International Journal of Computer Applications, 99(9), 4-8.

Kaastra, I. \& Boyd, M. (1996), "Designing A Neural Network For Forecasting Financial And Economic Time Series", Neurocomputing, 10(3). 215-236.

Karahan, M. (2011) "İstatistiksel Tahmin Yöntemleri: Yapay Sinir Ağları Metodu İle Ürün Talep Tahmini Uygulaması”, Doktora Tezi, Selçuk Üniversitesi, Sosyal Bilimler Enstitüsü, Konya.

Khansa, L. \& Liginlal, D. (2011) "Predicting Stock Market Returns From Malicious Attacks: A Comparative Analysis of Vector Autoregression And TimeDelayed Neural Networks", Decision Support Systems, 51(4). 745-759. 
Kutlu, B. \& Badur. B. (2009) "Yapay Sinir Ağları İle Borsa Endeksi Tahmini", Yönetim Dergisi, 20(63).

Mostafa, M. M. (2010) “Forecasting Stock Exchange Movements Using Neural Networks: Empirical Evidence From Kuwait", Expert Systems with Applications, 37(9), 6302-6309.

Olson, D., ve Mossman, C. (2003) "Neural Network Forecasts Of Canadian Stock Returns Using Accounting Ratios", International Journal of Forecasting, 19(3), 453-465.

Özkan, F. (2012) "Döviz Kuru Tahmininde Parasal Model ve Yapay Sinir Ağları Karşılaştırması", Business \& Economics Research Journal, 3(1).

Rençber, Ö. F. (2018) "Basamak Korelasyon Kohonen ve Anfis Yapay Sinir A $\breve{g}$ Modellerinin Sınıflandırma Performanslarının Karşılaştırılması: Lojistik Performans Endeksi Üzerine Uygulama”, Ege Akademik Bakis, 18(3). 521535.

Roh, T. H. (2007) "Forecasting The Volatility Of Stock Price İndex", Expert Systems with Applications, 33(4), 916-922.

Saraçoglu, O. G., Bagis, A., Konar, M., \& Tabaru, T. E. (2016) “ABC Algorithm Based Fuzzy Modeling of Optical Glucose Detection", Advances in Electrical and Computer Engineering, 16(3), 37-42.

Sönmez, F., Zontul, M. \& Bülbül, Ş. (2015) "Mevduat Bankalarının Karlılığının Yapay Sinir Ağları ile Tahmini: Bir Yazılım Modeli Tasarımı", Journal of Brsa Banking \& Financial Markets, 9(1).

Tektaş, A. \& Karataş, A. (2004) "Yapay Sinir Ağlari ve Finans Alanina Uygulanmasi: Hisse Senedi Fiyat Tahminlemesi", Atatürk Üniversitesi İktisadi ve İdari Bilimler Dergisi, 18(3-4). 337-349.

Ticknor, J. L. (2013) “A Bayesian Regularized Artificial Neural Network For Stock Market Forecasting”, Expert Systems With Applications, 40(14). 5501-5506.

Toraman, C. (2008) "Demir-Çelik Sektöründe Yapay Sinir Ağları İle Hisse Senedi Fiyat Tahmini: Erdemir AŞ ve Kardemir AŞ Üzerine Bir Tahmin Uygulaması", Muhasebe ve Finansman Dergisi, (39), 44-57.

Vaisla, K.S. ve A.K. Bhatt (2010) "An Analysis of the Performance of Artificial Neural Network Technique for Stock Market Forecasting", International Journal on Computer Science and Engineering, 2(6), 2104-2109.

Vaziri, B. S. (2006) "Assessing The Effect Of Macroeconomic Variables On Stock Price İndex İ Tehran Stock Exchange", (M.S. thesis), Alzahra University.

Yıldız, Ö. (2006) "Döviz Kuru Tahmininde Yapay Sinir Ağlarının Kullanımı", Yüksek Lisans Tezi, Eskişehir Osmangazi Üniversitesi, Sosyal Bilimler Enstitüsü, Eskişehir.

Yiğiter, Ş. Y., Sarı, S. S. \& Başakın. E. E. (2017) “Hisse Senedi Kapanış Fiyatlarının Yapay Sinir Ağları ve Bulanık Mantık Çıkarım Sistemleri İle Tahmin Edilmesi”, Kahramanmaraş Sütçü İmam Üniversitesi Iktisadi ve İdari Bilimler Fakültesi Dergisi, 7(1). 1-22. 